\title{
A Comparison of the Lasi language with English
}

\author{
Zahid $\mathrm{Ali}^{1}{ }^{1}$ Zafrullah Roonjho ${ }^{2}$ and Faiz Muhammad Brohi ${ }^{3}$
}

\begin{abstract}
Languages can be similar in sharing and transferring meanings/ideas, but they may be the different in their word order. The word order of English is subject-verb-object, while the word order of Lasi and Sindhi is subject-objectverb. This study explores out and compares the word order in Lasi and English at the sentence level. We can see a plenty of work on the structure of Pakistani languages. However, there is very less, almost zero work on Lasi's word order. Thus, this study compares the word order of English and Lasi. The data for the current study acquire through unstructured interview from native speakers of Lasi. Firstly, the word order of Lasi and Sindhi have been compared via the rules of word order of standard Sindhi. Secondly, the study compares the word order of Lasi and English through the theory of word order universals (Greenberg, 1963). The study finds that Lasi and Sindhi use SOV word order, whereas English uses SVO. The SOV word has been followed in the written and violated in spoken form; the natives do not usually follow this word order while speaking. However, this violation does not affect form and meaning of sentences; it is equally well-accepted like the written form.
\end{abstract}

Keywords: Word Order; Lasi; Sindhi; English; Dialect; Language.

\section{Introduction}

Language is the source of communication. Languages can be the similar in their basic aim of sharing and transferring meaning, but these can be the different in their structures , and Languages can be differentiated from one to another through structure (syntax); they may have same purpose to share and transfer meaning, but they may not have the same structure (Zahid, A., 2016; Cole, J. S., 2006). The word order or structure of Sindhi is subject, object and verb (Allana, 2010). The structure of English is subject, verb and object (Lashari, 2013; Veesar, Z. A., Sriniwass, S., \& Kadhim, K. A., 2015; Veesar, Z. A., Kadhim, K. A., \& Bagudu, R. S., 2015; Veesar, Z. A., Kadhim, K. A., Shah, S. A., \& Khuhro, R. A., 2016; Veesar, Z. A., \& Mustafa, G., 2021). Languages are the unique in their features (phonological, morphological, semantic, and syntactic). Lasi has its own syntactic feature, and its word order is subject, object and verb. Lasi is the dialect of Sindhi language (Allana,

\footnotetext{
${ }^{1}$ Department of English, Lasbela University of Agriculture, Water and Marine Sciences, Uthal, Lasbela, Balochistan, Pakistan.

${ }^{2}$ Department of English, Lasbela University of Agriculture, Water and Marine Sciences, Uthal, Lasbela, Balochistan, Pakistan.

${ }^{3}$ Institute of English Language and Literature, University of Sindh, Jamshoro, Sindh, Pakistan.
}

*)Corresponding Author.

Email: zahiimahii85@gmail.com 
2010). Mostly, it is spoken by the people of district Lasbela, Balochistan, Pakistan.

Lasbela was separated from Kalat and granted the status of district on 30th June 1954. The name Lasbela has been derived from Las which means a plain, and Bela, the Jungle. Lasi is a geographical name, which can be said for all the tribes other than Baloch, Med, Khoja, and Hindus, who are the residents of Lasbela (Hazara, 2011). It is the language of the people at Las. The form of the Sindhi spoken in Kohistan and in Las is called Lasi (Grierson, 1919a; 1919b). Sindhi at Las is called by the name of Lasi ;there are five major Lasi tribes: Roonjha, Jamot, Sheikh, Angaria and Burraf. These are called the Panj Raj, the five tribal confederacies, each raj, has many subgroups. There are many other tribes such as Sinars, Sangurs, Ganjas, Burfats, Chhutas and Khojas. Many Hindus are also the residents of Lasbela. They all belong to Arora caste. Babar, Gadras, Langhas and Kooris are also other tribes in Lasbela. The present study compares the word order in Lasi with word order in English at the sentence level.

\section{Literature Review}

\subsection{Word Order}

According to Zhao (2016), this study of the order of syntactic constituents of a language is the category of word order typology. The different languages have different word order in organizing the sentence structure. In the field of linguistics, word order may be defined as, the study of the arrangement of syntactic constituents in a language; it is known that the different languages have different orders. The word order means arrangement in which words come in sentences in the different languages (Zahid, A., 2016). The languages have contrasts in many ways; all the human languages will be similar if there is no variance in human languages. The syntactic order in a language- can be identified by studying theory of head parameters. It is also identified that some languages are head-initial, and some languages are head-final. The world languages have been classified according to their most order of constituents. Greenberg (1963), classified the different languages according to their most common word order. He divided these languages into three categories considering their constituent structures :-

Category 1. VSO (Verb, Subject, Object)

Category 2. SVO (Subject, Verb, Object)

Category 3. SOV (Subject, Object, Verb)

\subsection{Word Order in World Languages}

Dryer (2007), presented Word Order of Subject, Object and Verb of languages of the World as under:

Word Order of Languages of the world

1. Subject, Object, Verb 497

2. Subject, Verb, Object 435 


$\begin{array}{llc}\text { 3. } & \text { Verb, Subject, Object } & 85 \\ \text { 4. } & \text { Verb, Object, Subject } & 26 \\ \text { 5. } & \text { Object, Verb, Subject } & 9 \\ \text { 6. } & \text { Object, Subject, } & 4 \\ \text { 7. } & \text { Lacking the Dominant Word Order } & 172 \\ & & \\ & \text { Total } & \mathbf{1 2 2 8}\end{array}$

\subsection{Word Order in English}

In the linguistic category of the social world, English language has SVO language category since the common word order of English is subject, verb and object. Dryer (1991; 1992; 1997; 2007; 2013 \& Murphy, M. L., 1993) observed that English is neither verb-final nor verb initial since the subjects come before the verb while the object follows it. The category of SVO languages is the second most widespread than verb initial, but less widespread than verb-final languages. English is a head-first SVO language as in the following example.

English: Eat Apple. VS

The word order (SVO) of English is the most common, and it is the dominant order or unmarked orders as in the following example:

He plays cricket. SVO

The subject (he) in the above example precedes the verb plays and object follows it. This common word order may be changed according to context. When we emphasize on a word then the word order is changed. The Object has been placed from final position to the initial position changing the word order OSV as in the below example.

\section{Coffee, I like}

The word order is changed in many languages due to the topicalization or in question. The SVO order in English may be changed in an imperative sentence as in the following example:

\section{Example: Open the window.}

The verb open has been placed on the initial position and rest follows it. Ariyaratne, W. M. A. (2008), argued in his Ph.D. thesis titled "A contrastive study of word order in Sinhala and English" that in linguistic category of languages of the world English language is placed in the category of SVO language and SVO is the normal word order of English.

\subsection{Word Order in Sindhi}

According to Allana (2010), the word order of standard Sindhi is SOV. According to Cole (2006), Sindhi language has pragmatically neutral word 
order Subject-Object-Verb, but the order of these major constituents can be changed putting the phrase at the front of the sentence. The head word comes at the final position within the phrase, as in the noun phrase and verb phrase examples given below.

Sindhi: Hia hikrhi nandhri topi ahy

This is a small cap

Heya nandrhi topi

This small hat

This small hat

Amma khe chithee likhe

Mother to Letter wrote

Wrote a letter to mother

\subsection{Word Order in Lasi}

Lasi is the dialect of Sindhi language, so in the linguistic category; it is placed in SOV category, like word order of standard Sindhi. According to Weerakoon (1982), languages which have the same language family - are likely having closer similarity than languages that have the different families. Lasi and Sindhi belong to the same family Indo-Aryan language family. Thus, these have the same sentence structures.

Example of Lasi: Asson cricket kuduta SOV

We cricket play

$\begin{array}{lll}\mathrm{S} & \mathrm{O} & \mathrm{V}\end{array}$

We play cricket

\subsection{Word Order in Pakistani Languages}

Many languages are spoken in Pakistan, but word order of Pakistani languages is included here.

1. Urdu is the national language of Pakistan. Its word order is subjectobject-verb (Ahmed, T., 2002).

$\begin{array}{ccc}\text { Example. Main } & \text { aik mazmoon } & \text { likhta hon } \\ \text { I } & \text { an essay } & \text { write } \\ \text { S } & \text { O } & \text { V }\end{array}$

I write an essay

2. The word order in Punjabi is subject-object-verb (Hafeez, J., 2012) 


$\begin{array}{ccc}\text { Example. Aslam } & \text { khana } & \text { khanda piya hai } \\ \text { Aslam } & \text { meal } & \text { is having } \\ \text { S } & \text { O } & \text { V } \\ \text { Aslam is having his meal }\end{array}$

3. The word order in Saraiki is subject-object-verb (Junaid, 2012)

$\begin{array}{ccc}\text { Example. Aslam } & \text { khana } & \text { kh'nda paey } \\ \text { Aslam } & \text { meal } & \text { is having } \\ \text { S } & \text { O } & \text { V }\end{array}$

Aslam is having his meal

4. The typical word order in Brahui is subject-object-verb (Thompson, 2013)

5. The verb normally comes at the end of the sentence in Pashto (Najib, 2012).

Example: Da ketab dai

$\mathrm{S} \quad \mathrm{O} \quad \mathrm{V}$

This is a book

\section{Research Methodology:-}

The current study is on word order in Lasi; and also a comparison with word order in English at the level of sentence. Lasi is the dialect of Sindhi, thus; the word order of Lasi has also been compared with the word order of the standard Sindhi language. The study compares the word order of Lasi and standard Sindhi on the basis of the rules of standard Sindhi word order as presented by Allana (2010), and it also analysizes the word order of Lasi and English through word order universals by Greenberg (1963).

The current study is a qualitative in nature (Creswell, 2014; Kumar, 2006). Further, it uses the descriptive and exploratory research designs as it attempts to explore, analyze, and compare the word orders of Lasi, Sindhi and English. The oral data (spoken language) of the languages have been selected for the study. The data have been collected through unstructured interviews from the native speakers of Lasi and Sindhi (focusing on the ones who live in Uthal region of Lasbela, Balochistan). The English sentences are taken from the Greenberg' analysis. Due to some respondents, the study also uses, sometimes, the technique of semi-structured interview to collect the data. The participants have been given free and frank atmosphere so that they may speak freely and frankly, and they may not be camera conscious while recording and 
shooting the videos. The participants have been asked the simple and daily life questions about their routine life their job, status, family, past life, and future goal. The conservation uses the technique of flow with the flow so that they may speak the more natural language. Their interviews have been recorded, and later transcribed into the written form for the sake of analysis. There were many places where we felt 'fear of failure' among participants that is why they were given free atmosphere to speak anything they like to. By the term 'fear of failure' we mean to say that the respondents felt that they might speak something wrong that is why they were felt conscious while speaking. To avoid such a situation, they were given free atmosphere to speak naturally. Our main concern was to participate in the conversation and record their language so that we may analyze the use of SOV word order in their language.

\subsection{Data Analysis}

The theory of the rules of word order arrangement of standard Sindhi by Allana (2010), has been used as a theory/model for analyzing and comparing the word order of Lasi and standard Sindhi. They focus on the theory of 'Word Order Universals' by Greenberg (1963), has been taken as an analytical framework for the analysis and comparison of word order in Lasi and English. Some of the Allana's rules of word order arrangement of standard Sindhi and Greenberg's word order universals are mentioned below;-

Some rules of word order arrangement of the standard Sindhi

(i) Enlargement of subject always precedes subject in every sentence of standard Sindhi Language. For instance:-

\section{Enlargement of Subject}

Kind leader of Sindh Miyan Kalhoro

\section{Subject}

Miyan Kalhoro

(ii) Verb always comes at the final position in each sentence of the standard Sindhi Language. For example:

'Mun ghar adayo

'I a home built

I built a home.

The verb 'adayu = built' in the above example has been used at the end of the sentence.

(iii) If the sentence which consists of transitive verb, then the order of words in every sentence of standard Sindhi Language would be as under:

$$
\begin{aligned}
& \text { Subject }+ \text { Object }+ \text { Verb or } \\
& \text { Enlargement of subject } \rightarrow \text { Subject } \rightarrow \text { Enlargement of object } \rightarrow \\
& \text { Object } \rightarrow \text { enlargement of verb } \rightarrow \text { verb }
\end{aligned}
$$


(iv) If the sentence consists of intransitive verb, then the order of words in every sentence of standard Sindhi Language would be as under:

$$
\text { Enlargement of Subject } \rightarrow \text { Subject } \rightarrow \text { Adverb } \rightarrow \text { Verb }
$$

(v) Adjective always comes before subject very close to it.

(vi)Enlargement of verb always precedes, and adverb always comes before verb.

(vii) Preposition is always placed after the noun, pronoun, adjective and adverb but it is placed very close to it.

\subsection{Word Order Universals}

Greenberg (1963), presented word order universals in a paper titled as some universals of grammar with reference to the order of meaningful elements. $\mathrm{He}$ used 30 language samples and set up forty (45) implicational statements, many statements are related to word order. The followings are some Greenberg's word order universal statements.

(i) If the declarative sentence has common subject as well as object, then the governing arrangement would always be a single, in this situation subject comes before an object.

(ii) SVO, SOV, VSO are the most common orders. These are due to reasons of thematic or pragmatic. On the side of thematic ; subjects are commonly Agents and objects are commonly Patients, and Agents are considered more important than Patients meanwhile it is on account of Agent's action that for this reason something happens to the Patient. Therefore, Agent comes before patient. In the pragmatics, commonly our interest is in the subject because it is the Agent, and it is the more probably to be human too. Subjects are commonly also topics, and topics are usually placed at the initial position of the sentence.

(iii) The genitive would almost come after the governing noun in prepositional languages, but it would always come before the noun postpositional languages. Thus, generally both [PP P NP] and [NP N NP gen] or [PP NP P] and [NP NP gen N]. These appearances alike head dependent order, but in the structural positions this specific connection is the peculiar, at least for configurational languages, as the object of a preposition is a complement whereas the "genitive" is generally taken to be subject like (in terms of theory, a specifier). There is also possibility that genitives do not make an identical structural category cross-linguistically: they might be subjects (specifiers) in some languages, complements in others, and adjuncts in others. 
(iv) The dominant word order VSO languages have always prepositions. If a language has [V NP NP] (or whatever other structure a VSO language may have), it is [PP P NP]. It is a straightforward connection of head-complement order. But for SVO languages, which is likely have the same pattern, this is less correct.

(v) The languages having normally SOV order use postpositions. If a language has [VP NP V] it commonly has [PP NP P]. Another straightforward head-complement (in fact, head-object) connection.

(vi) If the genitive comes after the governing noun and languages having dominant order SOV, then the adjective would come after the noun.

(vii) If a language has both [S NP [VP NP Vhead] and [NP N head NPgen], then it has [NP Nhead AP]. It is not clear why this would work out this way.

\subsection{Analysis of Lasi, Sindhi and English Sentences}

As stated earlier, this research work compares and analyzes the word order in Lasi and English at the level of sentence. Since Lasi is one of the dialects of Sindhi (Ameen, M. \& Ali, Z., 2021; Zahid, A., 2016), the word order of Lasi has also been compared with the word order of Standard Sindhi. The word orders of Lasi, Sindhi and English have been analyzed and compared in the simple sentences, assertive/declarative sentences ; interrogative sentences, and negative sentences at sentence level. The word order of Lasi and Sindhi have been compared through Allana's (2010) rules for the construction of sentences in standard Sindhi, and Greenberg's (1963) word order universals have been used to compare English and Lasi word order. These universal statements provide a framework for checking the word order in a particular language.

\subsubsection{Word Order in Simple Sentence in Lasi}

A sentence having only one subject and one predicate or a sentence having one finite verb is called simple sentence (Wren \& Martin, 2015).

For example: He plays a game.

Example 4.2.1 Simple sentence of Lasi

$\begin{array}{llll}\text { Moonjho } & \text { pehe } & \text { schoolem } & \text { parahae tu } \\ \text { Moonjho } & \text { pehe } & \text { schoolem } & \text { parahae tu } \\ \text { My } & \text { father } & \text { school in } & \text { teaches }\end{array}$

My father teaches in school.

Example 4.2.2 Simple sentence of Sindhi

Muhinjo bhao university mein parahae tho 


Maanjho bhao University mein parahae tho
My brother University in teaches

My brother teaches in university.

Example 4.2.3 Simple sentence of English

The boy ran a mile.

The word order in Lasi, Sindhi and English in the simple sentences has been compared in the above sentences. It can be argued that the enlargement of subject is placed before the subject in the three languages. These languages have similarity in using enlargement of subject and the subject. The other observation is that these languages use an extension or adverbial qualification with verb, but there is a difference in the order of verb and an extension or adverbial qualification. The prepositional phrases are placed before verb in Lasi and Sindhi; while in English, the verb is placed before prepositional phrases and extension or adverbial qualification. English uses preposition while Sindhi and Lasi use postpositions (class mein = in class). We can also see the difference between the use postpositions in Lasi and Sindhi; Sindhi uses a separate word to show postposition while Lasi uses it with the noun (Sindhi: Class mein; Lasi: Classm). Last 'm' sound in the word 'class' shows the position which means 'in class'.

According to Greenberg (1963), in a language with dominant SOV order, there is no alternative basic order, or only OSV as the alternative, and then all adverbial modifiers of the verb likewise precede the verb.

The Lasi and Sindhi usually use SOV word order, and it is a dominant word order in both languages, but some other word orders are also possible in oral communication without affecting meanings of the sentences. OSV, OVS, VOS, VSO, and so forth. Word orders are also applied in these languages without affecting the forms and meanings of sentences. Spoken Lasi can also violate the places of adverbs and postpositions.

\subsubsection{Word Order in Assertive/Declarative Sentences in Lasi}

An assertive or declarative sentence presents a statement or assertion (Wren \& Martin, 2015). For example: The teacher was teaching the class.

The sentences in which speaker describes sentences in a common style (Allana, 2010).

Example 4.3.1 Lasi

\section{Asson cricket kuduta.}

$\begin{array}{llcl}\text { Asson } & \text { cricket } & \text { kudu ta } & \text { SOV } \\ \text { We } & \text { cricket } & \text { play } & \end{array}$


S O V

We play cricket

Example 4.3.2 Sindhi

Akber ambu khae tho

$\begin{array}{lccr}\text { Akbar } & \text { ambu } & \text { khae tho } & \text { SOV } \\ \text { Akbar } & \text { mango } & \text { eats } & \\ \text { S } & \text { O } & \text { V } & \\ & \text { Akbar eats an apple } & \\ \text { Example } & 4.3 .3 & \text { English } & \\ \text { They play hockey } & & \\ \text { They } & \text { Play } & \text { hockey } & \text { SVO } \\ \text { S } & \text { V } & \text { O } & \end{array}$

The analysis shows that word order of Lasi and Sindhi in the declarative sentences is subject, object and verb (SOV) by following the rules of standard Sindhi sentence structure presented by Allana (2010), whereas the arrangement of words in the declarative sentences of English is subject, verb, object (SVO).

According to Greenberg (1963), if the declarative sentence has common subject as well object, then the governing arrangement would always be the single, in this situation subject comes before an object. The subject is placed before an object in the declarative sentences of Lasi, Sindhi and English. It is analyzed that mostly these languages follow the statement or rule of Greenberg, but these rules are not followed usually in oral communication in Lasi and Sindhi. Both the languages have normally subjectobject-verb (SOV) word order, but common word order of both the languages is the flexible to be changed in an informal speech or oral discourse.

\subsubsection{Word Order in Questions in Lasi}

A sentence in which a question being asked is known as an Interrogative Sentence (Wren \& Martin, 2015). The interrogative sentences are those sentences in which questions are asked or speaking style of speakers look like questions (Allana, 2010).

Example 4.4.1 Lasi

\section{Toon kith tu rehee?}

$\begin{array}{cll}\text { Toon kith tu } & \text { rehee? } \\ \text { You } & \text { where } & \text { live }\end{array}$


S Wh-Q V

Where do you live?

Example 4.4.2 Sindhi

$\begin{array}{ccc}\text { Tawhan } & \text { kithe tha } & \text { raho? } \\ \text { Tawhan } & \text { kathe tha } & \text { raho? } \\ \text { You } & \text { Where } & \text { live } \\ \text { S } & \text { Q } & \text { V }\end{array}$

Where do you live?

In the above examples of Lasi and Sindhi word order of both the languages is the same in the interrogative sentences.

Example 4.4.3 English

Where do you live?

$\begin{array}{lll}\text { Where do } & \text { you } & \text { live? } \\ \text { Wh-Q } & \text { S } & \text { V }\end{array}$

The analysis of the above interrogative sentences shows that whquestion or question word in Lasi and Sindhi is used in the middle of the sentence, but in English wh-question or question word comes at the initial position in sentence, and the verb is placed at the final position in sentences in three languages.

\subsubsection{Word Order in Negative Sentences}

The negative sentences are those sentences which have negative sense (Allana, 2010). According to Allana (2010), negative word is placed before verb in the negative sentence of Sindhi.

Example 4.5.1 Negative Sentence in Lasi

$\begin{array}{lll}\text { Result } & \text { kona } & \text { aayo. } \\ \text { Result } & \text { kona } & \text { aayo } \\ \text { Result } & \text { did not } & \text { declare-past } \\ \text { O } & \text { Negation } & \text { V }\end{array}$

The result was not declared. 
Example 4.5.2 Negative Sentence in Sindhi

$\begin{array}{cclc}\text { Maa } & \text { ute } & \begin{array}{c}\text { kona } \\ \text { kona }\end{array} & \begin{array}{c}\text { huwos. } \\ \text { huwos }\end{array} \\ \text { I } & \text { there } & \text { Not/No } & \text { was } \\ \text { S } & \text { O } & \text { Negation } & \text { V }\end{array}$

I was not there.

The above examples 4.5.1 and 4.5.2 present the sentence structure of Lasi and Sindhi in negative sentences, where subjects are placed at the initial position, the negative marker $(\mathrm{Nm})$ are placed before verbs, and verbs are placed at the end of the sentences. According to Allana (2010), the negative word is placed before verb in the negative sentence of Sindhi.

Example 4.5.3 Negative Sentence in English

\section{He does not go to university.}

He does not go to university

S Aux Neg V O

In above examples of Lasi, Sindhi and English in negative sentences, subjects are placed at the initial position, auxiliary negative marker $(\mathrm{Nm})$ are placed before verbs in three languages, but the only difference is on the position of object. The objects in Lasi and Sindhi are placed before the negative marker $(\mathrm{Nm})$ while in English object is placed at the end of the sentence.

\section{Conclusion}

The main aim of this study is to explore, analyze and compare word order in Lasi and English at the sentence level. Lasi is the dialect of Sindhi (Allana, 2010; Zahid Ali, 2016); thus, the word order of Lasi has also been compared with standard Sindhi. The word order of Lasi has been compared with English and Sindhi in the Simple sentences, assertive/declarativesentences ;interrogative sentences, and negative sentences at the level of sentence. The word order of Lasi has been compared with standard Sindhi on the basis of some rules for the construction of sentences in standard Sindhi presented by Allana (2010) and word order of Lasi has been compared with English on the basis of Greenberg's word order universals (1963). Many statements are related to word order. These universal statements provide a framework for checking the word order in a particular language.

The study finds that Lasi has subject-object-verb (SOV) word order according to standard Sindhi language. According to Allana (2010) a subject comes at the initial position, an object in the middle and a verb at the final 
position of the sentence in Sindhi. Whereas the word order of English is subject-verb-object (SVO).

The results of this study show that dominant word order in Lasi and Sindhi is subject, object and verb (SOV), but in both the languages some other word orders are also possible in an oral communication without affecting the meaning of the sentences, whereas such the flexibility has not been seen in English written and spoken in this perspective. According to Weerakoon (1982), languages which have the same language family are likely having closer similarities than the languages that have the different families.

Sindhi is a member of the Indo-Aryan sub-family and English is a member of the Germanic sub-family. Therefore, English has a different word order from Lasi and Sindhi. It can be said that Lasi and Sindhi are more flexible than English and have free word order.

The analysis of the data indicated that the enlargement of subject is placed before the actual subject in the three languages including Lasi, Sindhi and English. Thus, showing the same pattern of using enlargement of subject and subject. The wh-questions or question words in Lasi and Sindhi are placed before verb, verbs come at the final position in the sentence, whereas in English question words are placed at the initial position of the sentence. The objects in Lasi and Sindhi are placed before the negative marker (Nm) while in English an object is placed at the end of the sentence.

Lasi, Sindhi and English have used subjects at the initial position of the sentence, verbs in English in the middle and verbs in Lasi are used at the end of the sentence. However, the only difference is in the use and position of prepositions, postpositions, the extension, or adverbial qualification. The extension or adverbial qualification in Lasi is placed before verb; while in English, it is placed after verb at the end of sentence. The main finding of the study is that English uses the given word order (SVO) in its written and spoken forms without any violations of place and positions of constituents. However, Lasi and Sindhi differ in this sense; they use SOV word order in their written form without violations, but they have flexibility in their spoken forms. Lasi and Sindhi spoken forms violate the SOV word order in the place and position of subjects, objects, verbs, postpositions, adverbs, and adjectives. However, such the violations do not affect the forms and meanings of the sentences ; they are equally accepted and applied in their routine life conversation.

\section{References}

Ahmed, T., \& Alvi, S. (2002). English to Urdu translation system. manuscript, University of Karachi.

Allana, G.A. (2010). A Descriptive Grammar of Sindhi Language. Sindhi Language Authority (SLA), National Highway, Hyderabad, Sindh, Pakistan. 
Ariyaratne, W. M. A. (2008) contrastive study of word order in Sinhala and English. Institute of Advanced Studies in English Aundh, Pune.

Cole, J. S. (2006). Sindhi. In Encyclopedia of Language \& Linguistics (pp. 384-387). Elsevier Ltd.

Dryer, M. S. (1991). SVO languages and the OV: VO typology1. Journal of linguistics, 27(2), 443-482.

Dryer, M. S. (1992). The Greenbergian word order correlations. Language, 81-138.

Dryer, M. S. (1997). On the six-way word order typology. Studies in Language. International Journal sponsored by the Foundation "Foundations of Language", 21(1), 69-103.

Dryer, M. S. (2007). Word order. Language typology and syntactic description. Volume 1: Clause structure. Ed Timothy Shopen.

Dryer, M. S. (2007). Word order. Language typology and syntactic description. Volume 1: Clause structure. Ed Timothy Shopen.

Dryer, M. S. (2013). On the six-way word order typology, again. Studies in Language. International Journal sponsored by the Foundation "Foundations of Language", 37(2), 267-301.

Greenberg, J. (1963). Some universals of grammar with particular reference to the order of meaningful elements. In J. Greenberg, ed., Universals of Language. 73-113. Cambridge, MA.

Grierson, G. A. (1919a). Linguistic survey of India: Indo-Aryan family, northwestern group: Specimens of Sindhī and Lahndā, Vol. VIII, Part I. Calcutta, India: Government of India.

Grierson, G. A. (1919b). The linguistic survey of India. Indo-Aryan family north-western groups. Specimens of Sindhi and Lahnda, Vol. III, Part I.

Hazara, Z.A. (2011). (Additional Chief Secretary) Development, District Development profile. UNICEF Provincial Office Baluchistan, Quetta

Hafeez, J. (2012). Who is the M/Other of the Two? A Comparison of the Syntactic Systems of Punjabi and Siraiki. Language in India. 72.

Lashari, M.A., \& Somoro. A. A. (2013). Subject Verb Agreement in Sindhi and English; A comparative study; language in lindia.

Maisarah, M., Kadhim, K. A., \& Veesar, Z. A. (2016). Semantic Analysis of Theta Roles of Verbs in the Mah Meri Language. English Review: Journal of English Education, 5(1), 49-70.

Murphy, M. L. (1993). Discourse markers and sentential syntax. cop., 23(1).

Weerakoon, H. (1982). The noun-phrase in Sinhala and English: a constructive study (Doctoral dissertation).

Wren, P. C., \& Martin, H. (2002). High school grammar and composition. Ram Nagar, New Delhi: S. Chand \& Company Ltd.

Veesar, Z. A., Sriniwass, S., \& Kadhim, K. A. (2015a). A Comparison of Theme Theta Roles in English and Sindhi. Language \& Communication, 2(1), 77-89. 
Veesar, Z. A., Kadhim, K. A., \& Bagudu, R. S. (2015b). The Most Prominent Theta Roles in the Sindhi Language: The Hierarchy. International Journal of Foreign Language Teaching and Research, 3(12), 11-24.

Veesar, Z. A., Kadhim, K. A., \& Sriniwass, S. (2015c). Establishing the Thematic Structure and Investigating the most Prominent Theta Roles Used in Sindhi Language. International Journal of Applied Linguistics and English Literature, 4(4), 216-230.

Veesar, Z. A., Kadhim, K. A., Shah, S. A., \& Khuhro, R. A. (2016). Argument Structure of Sindhi Verbs: An Analysis of Thematic Relations. Language in India, 16(2).

Veesar, Z. A., \& Mustafa, G. (2021). A Comparative Analysis of Retroflexion in Romani and Lasi: NA. Journal of Education \& Humanities Research, University of Balochistan, Quetta-Pakistan, 11(1), 78-95.

Zahid, A. (2016). Morphosemantic and syntactic analysis of verbs in Sindhi/Zahid Ali (Doctoral dissertation, University of Malaya). 